\title{
Pubertas praecox due to hypothalamic hamartoma: report of two cases surviving surgical removal of the tumour
}

\author{
D. W. C. NORTHFIELD AND D. S. RUSSELL \\ From The London Hospital
}

The association of pubertas praecox with tumours of the third ventricle has long been recognized. The tumour is sometimes a congenital malformation, or hamartoma, composed of redundant brain tissue. This comprises a haphazard assembly of neurones, bundles of nerve fibres, and neuroglial cells in more or less appropriate proportions and distribution. These 'tumours' are usually about 1 to $2 \mathrm{~cm}$. in diameter, but may be smaller or larger; they consistently lie at the base of the brain in the region of the tuber cinereum and mammillary bodies, to some part of which they are usually attached by a pedicle so short that they can be described as sessile. Occasionally the mass lies free in the leptomeninges which provide a capsule.

Previously recorded cases will not be reviewed here: readers are referred to the excellent survey by Schmidt, Hallervorden, and Spatz (1958), who also reported four new cases. Several more recent publications are discussed by Wolman and Balmforth (1963).

The present paper is concerned with two cases in which prolonged survival followed operative removal of the hamartoma. In particular, the modifying effects of operation upon the pre-existing pubertas praecox will be noted.

We are not, at the time of writing, acquainted with any similar records. In case 2 of the communication by List, Dorman, Bagchi, and Bebin (1958) the patient had lived for nine months after a limited biopsy of the tumour but, as the authors recognize, this period was too short for a full assessment of the effects of operation. But since, as we shall argue later, the mechanism whereby pubertas praecox is promoted by the tumour in question is debatable, the consequences of complete operative removal are of considerable theoretical and clinical importance.

\section{CASE REPORTS}

CASE 1 M.T., a male, was born on 18 June 1955, by forceps delivery, weight $4 \frac{1}{2} \mathrm{lb}$. His mother had toxaemia of pregnancy. At the age of 8-9 months he developed pubic hair, at first downy and later more profuse. His development was otherwise not remarkable, but his mother had noticed that he was always physically strong and she thought that he was not quite normal.

At the age of 11 months he was admitted to the Hospital for Sick Children, Great Ormond Street, where no physical abnormalities were noted beyond precocious genital development, facial acne, and greasiness of the skin. The extremities, on $x$-ray examination, showed that bone development was only a few months in advance of the standard. Testicular biopsy showed considerable cellular proliferation in the tubules, simulating an adult pattern. Ventriculography revealed deformation of the third ventricle, indicative of a hypothalamic tumour. However, in the absence of signs of raised intracranial pressure, or of cerebral impairment, the child was discharged with the prescription of phenobarbitone and potassium bromide to diminish his excitability.

When readmitted, at the age of 2 years, his condition was unchanged, except that mental retardation was suspected. This was confirmed on further admission a year later.

At the age of $3 \frac{1}{2}$ years the boy was admitted to the London Hospital. On examination he was abnormally tall ( $3 \mathrm{ft} .10$ in. $(1 \cdot 168 \mathrm{~m}$.)) and powerfully built (wt. $4 \mathrm{st}$. $5 \mathrm{lb}$. (27.67 kg.)). His limbs and torso were disproportionate and the external genitalia fully developed (Fig. 1). Secondary sexual characters were obvious, his voice being deep and husky whilst his facial features were heavy, with a growth of downy hair on the sides of his cheeks, and heavy eyebrows. Hair grew thickly over the scalp. Mental retardation was obvious; he talked little, but frequently laughed and giggled. He was never seen to make sexual advances towards females. The skull circumference $(51.5 \mathrm{~cm}$.) was proportionate to his stature and neurological examination disclosed no abnormality.

Investigations Chemistry of blood and of urine was normal. The cerebrospinal fluid contained less than $20 \mathrm{mg}$. of protein per $100 \mathrm{ml}$., and less than 1 cell per c.mm. Urine contained $1.3 \mathrm{mg}$. of 17-ketosteroids in 24 hours. Skeletal radiographs for bone age corresponded to the appearances normal at $\mathbf{1 3}$ years; skull radiographs were normal.

Air encephalogram The lateral and third ventricles were dilated; air in the interpeduncular and chiasmal 


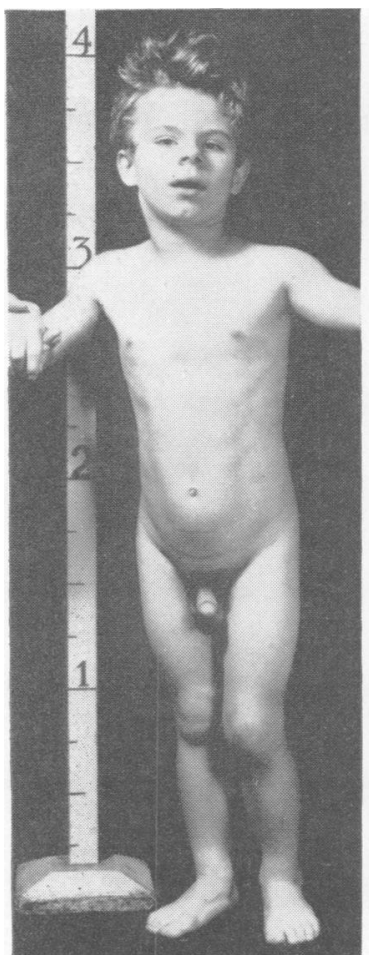

FIG. 1 .
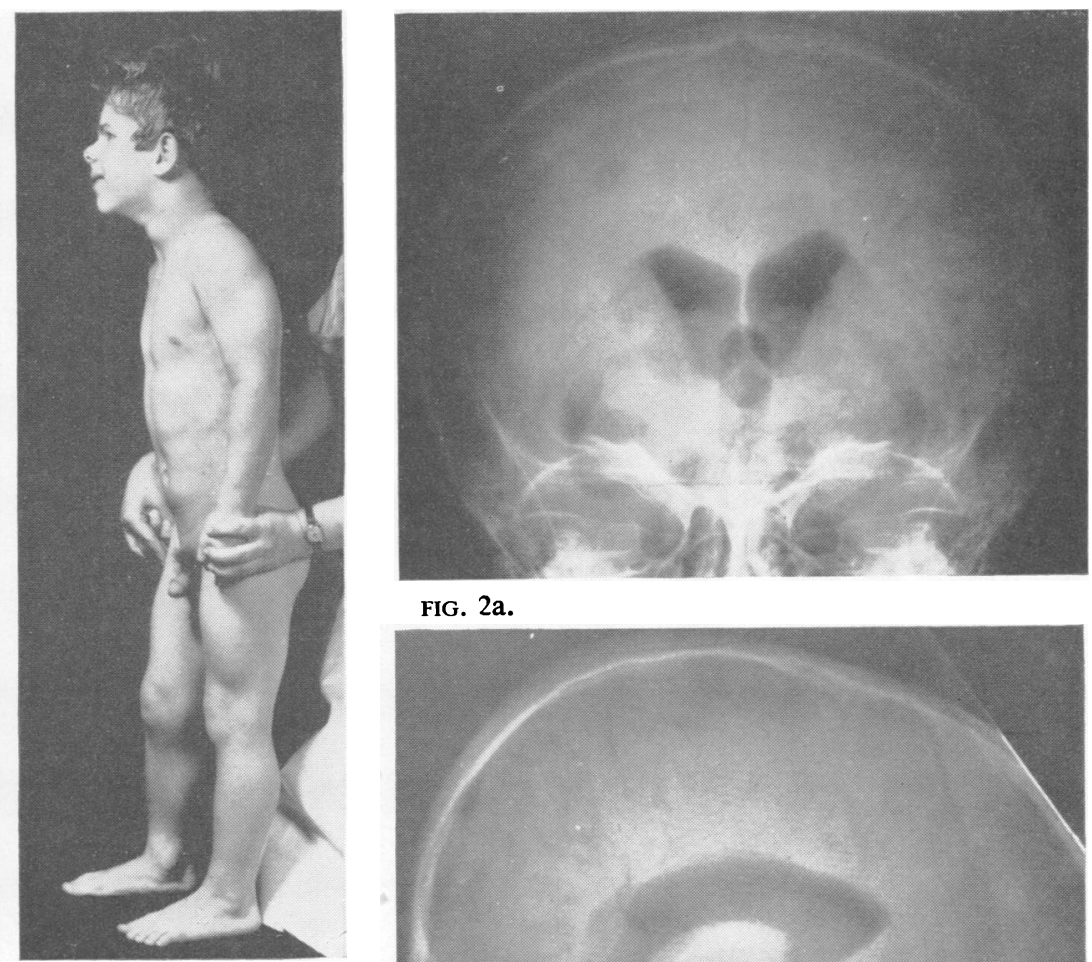

FIG. 2 a.

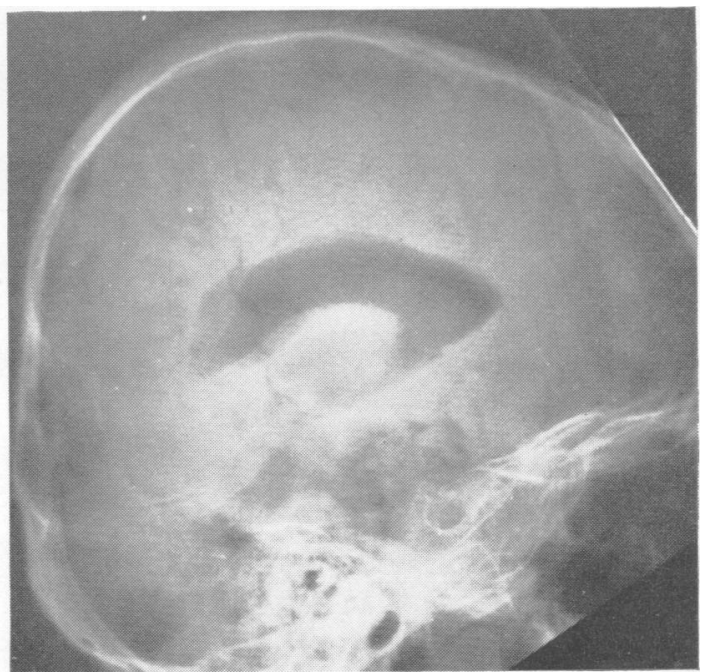

FIG. $2 b$.

$1 \cdot 3 \mathrm{~g}$.) of firm pink tissue with coarsely lobulated smooth glistening outer surface and a more haemorrhagic and ragged opposite surface (Fig. 4) was received. Cut surfaces were homogeneous, pale, and grey. Accompanying this were numerous smaller pieces (together $2 \mathrm{~cm}$. diam. and up to $0.8 \mathrm{~cm}$. high; weight $1 \cdot 2 \mathrm{~g}$.) of similar tissue.

Microscopic pathology The tissue contains mature nerve cells, varying considerably in size and shape, and dispersed fairly evenly throughout all areas (Fig. 5a). Loyez and Bielschowsky preparations demonstrate numerous myelinated nerve fibres, often in conspicuous leashes. The latter often lie beneath, and parallel with, the surface of the hamartoma. Glial cells are scattered haphazard throughout the tissues; numerically they correspond to the quota usually seen in normal cerebral grey matter. The only cytological peculiarity is the occurrence of occasional discrete nests of small undifferentiated cells with spherical, deeply haematoxyphil nuclei containing a central nucleolus. Their appearance 

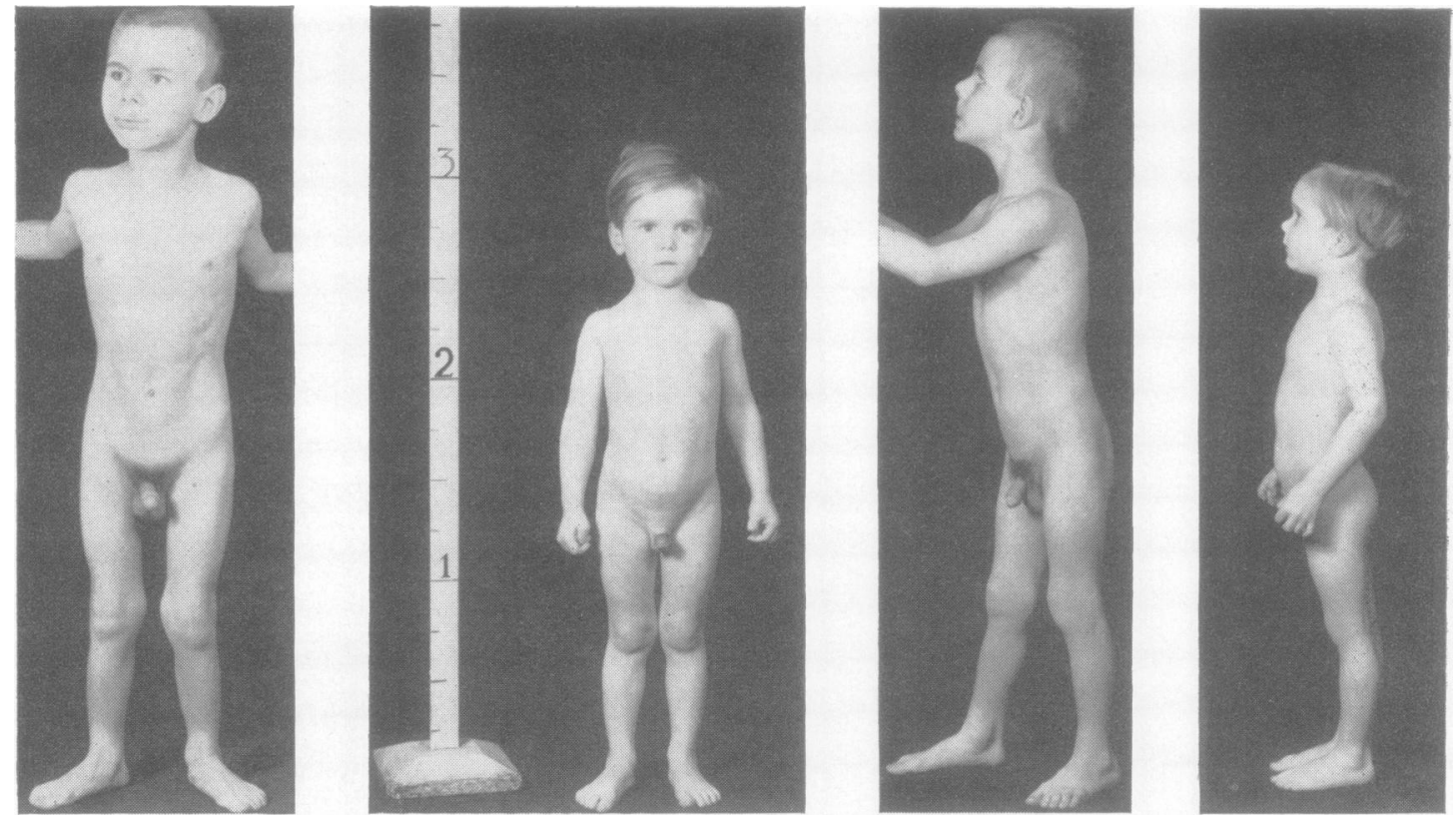

FIG. 3. M.T. 24 days after operation; note marked loss of muscle substance compared with Fig. 1 (smaller child is controlo of same age).

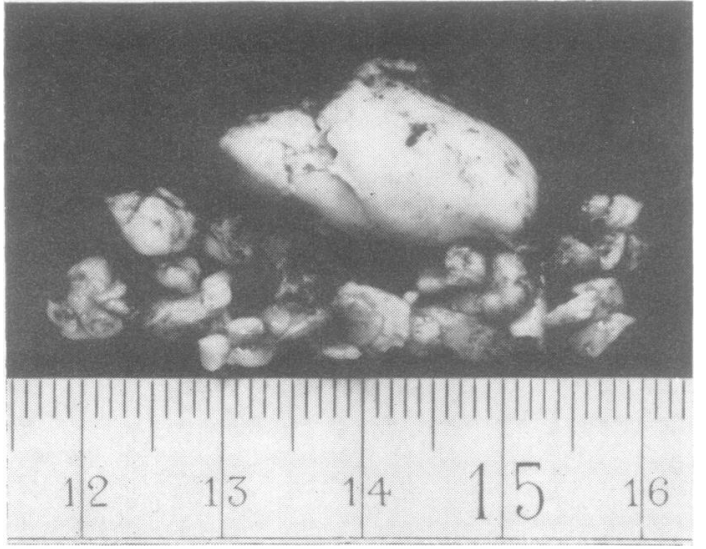

FIG. 4. Tumour from case 1 . suggests that they are primitive neuroblasts, but Bielschowsky preparations failed to substantiate this. No pituitary stalk tissue was found amongst the fragments.

Subsequent course This boy has been under regular observation since the time of operation up to his presentô. age of 10 years and 10 months. The following table gives? his successive records of weight and height.

\begin{tabular}{lllll} 
Age $(y r)$. & Weight (st. lb.) & Height (ft. in.) \\
\hline $3 \frac{1}{2}$ & 4 & 5 & 3 & 10 \\
4 & 4 & 2 & 4 & \\
$4 \frac{1}{2}$ & 4 & 4 & 4 & 2 \\
5 & 4 & 8 & 4 & $3 \frac{1}{2}$ \\
$5 \frac{1}{2}$ & 5 & 1 & 4 & 4 \\
$6 \frac{1}{2}$ & 5 & 6 & 4 & 6 \\
8 & 5 & 10 & 4 & 8 \\
9 & 6 & 2 & 4 & $9 \frac{1}{2}$ \\
$10.10 / 12$ & 6 & $4 \frac{1}{2}$ & 4 & $10 \frac{1}{2}$
\end{tabular}

The most obvious physical change lay in a rapid loss of excessive muscularity, even apparent three weeks after operation (Fig. 3), so that the 'infant Hercules' appearance gave place to a more normal slimness of body contours. His present appearance is shown in Figure 6. But there was no retrogression in genital development: this has remained static. He continued to speak with a deep, husky voice but, as time went on, this became less noticeable. He remained mentally backward and was restless, excitable, and difficult to examine. Later there was a gradual improvement also at this level. From the age of $\mathbf{8}$ he has attended a boarding school for backward children, and has made good progress. At the age of 10 he was able to converse much more freely and sensibly, and his movements were more composed. Physically, 


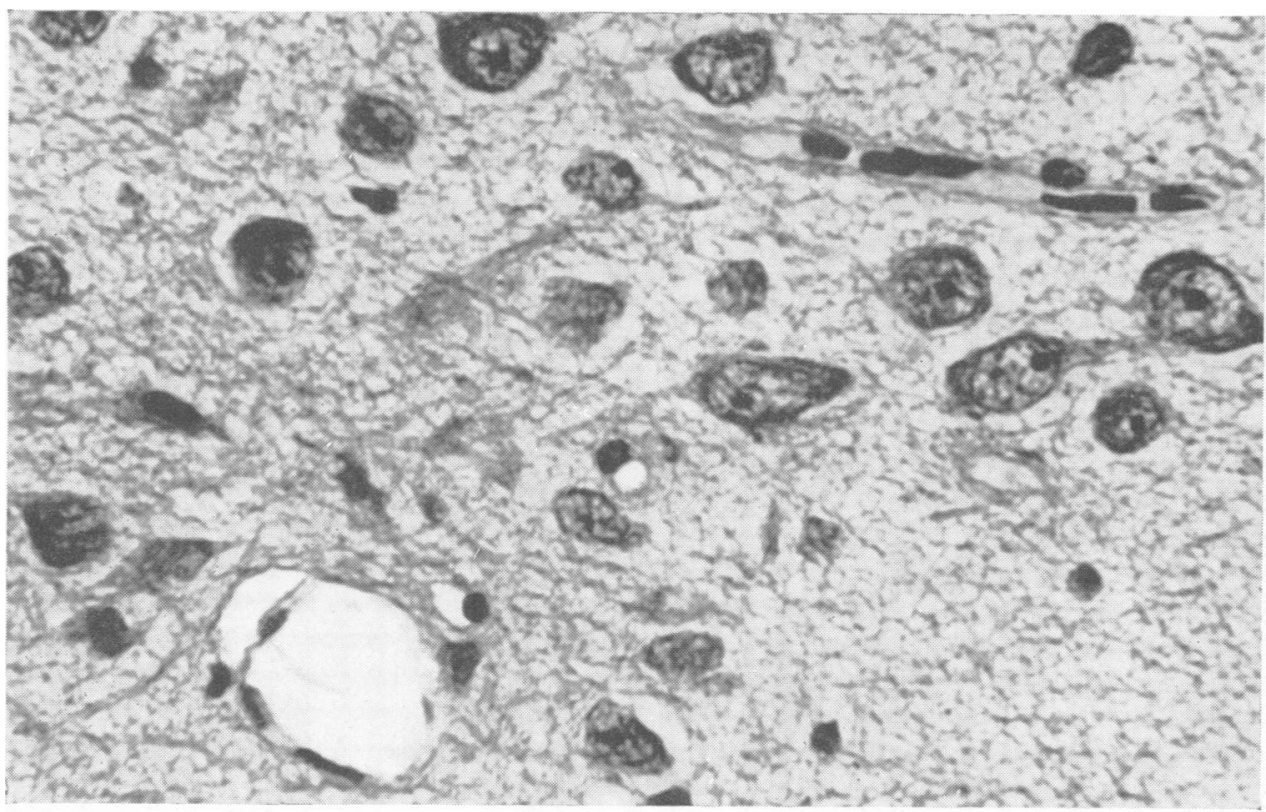

FIG. 5a.

Tumour

from case 1.

Haema-

toxylin and

eosin $\times 500$.

FIG. $5 b$.

Tumour

from case 2.

Haema-

toxylin and

eosin $\times 175$.

Neurones and scattered

glial cells.

FIG. 5a.

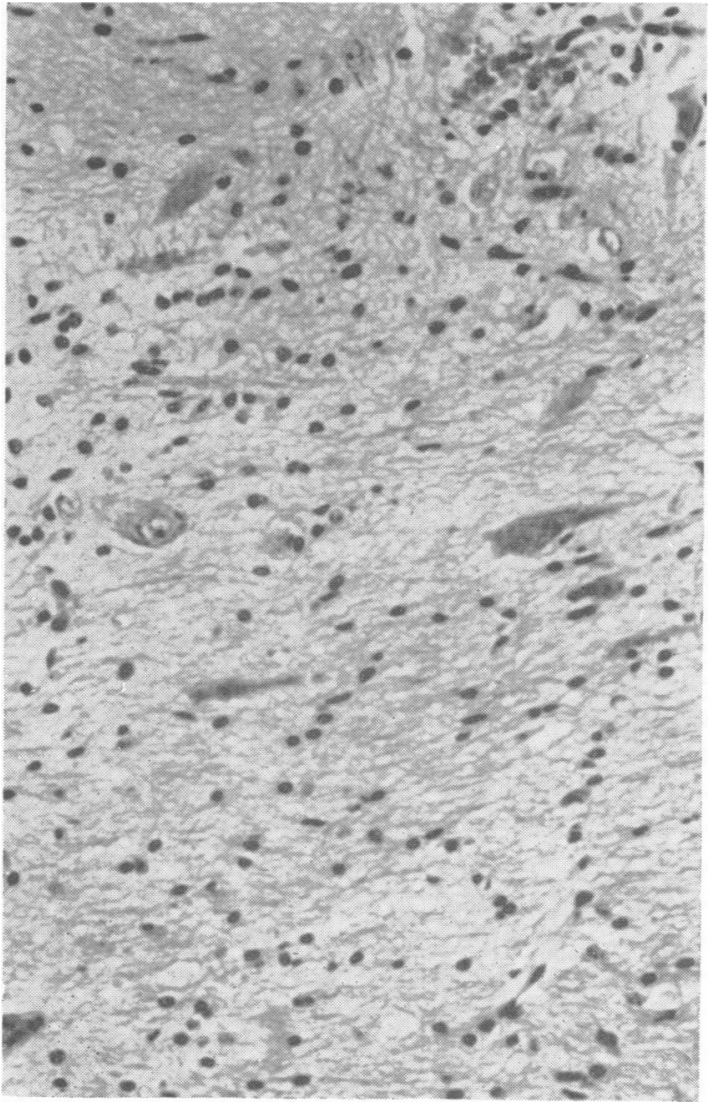

FIG. $5 b$. apart from the genitalia, his outward appearance would pass as normal for a boy of his age.

CASE 2 S.D., a male, was born on 22 November 1958 and was the first child of Malay parents. Pregnancy and labour had been normal. When 19 months old, his parents noticed the growth of pubic hair, enlargement of the genitalia, and frequent erections. His Malay doctor prescribed prednisone which seemed to have a slight moderating effect on these features. In this country he was admitted, at the age of 3 years 8 months, to the Queen Elizabeth Hospital for Children, Hackney Road, London, where he was recorded as a large sturdy child with excessive hirsuties, muscularity, and genital development. Physical features were otherwise normal. Special investigations of the blood picture and chemistry of blood and urine revealed no significant aberration; 17 -ketosteroid excretion in urine was $1.0 \mathrm{mg}$. in 24 hours. His bone age was assessed radiographically to be that of a 6-year-old child. Height was $3 \frac{1}{2} \mathrm{ft}$. $(1.066 \mathrm{~m}$.); weight 3 st. 12 oz. (19.39 kg.). On 1 August 1962 he was transferred to the London Hospital. On examination he was nervous and apprehensive but appeared of normal mentality, and his voice was normal for a child. Hirsuties was generalized but especially marked on the upper lip and pubis (Fig. 7). The external genitalia were enlarged. Neurological examination elicited no abnormal features. A skull radiograph was normal.

Air encephalography There was slight enlargement of the ventricles and of the aqueduct, and the fourth ventricle was slightly displaced posteriorly away from the clivus. Air in the interpeduncular cistern outlined a small round mass situated above and behind the dorsum sellae (Fig. 8).

Operation The procedure (14 August 1962) adopted was the same as in case 1 . But here the tumour displaced 

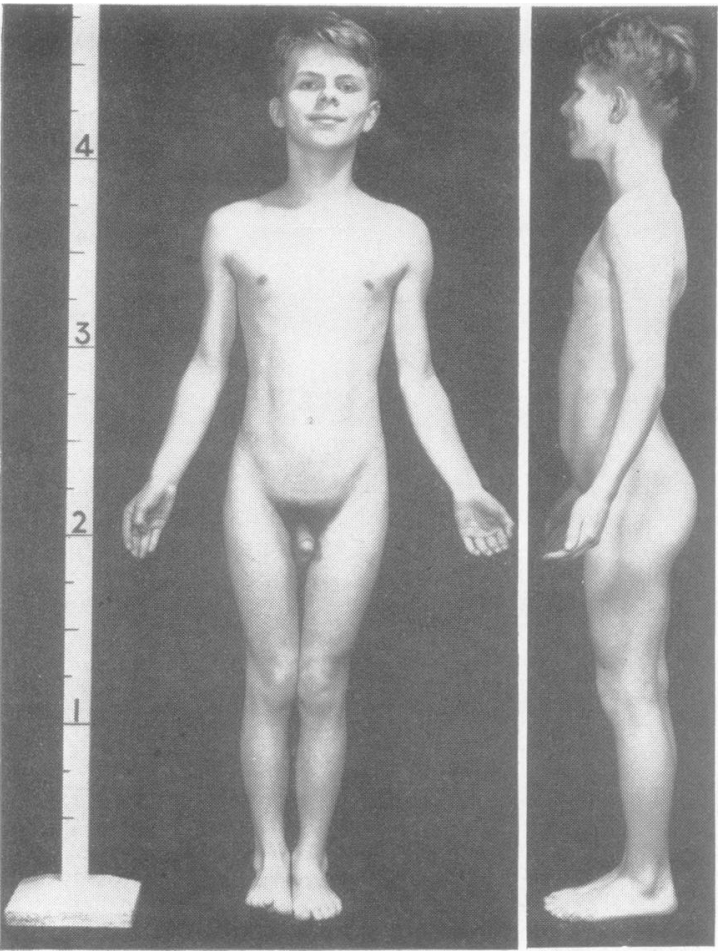

FIG. 6. M.T., present appearance, aged 10 years 10 months.

the pituitary stalk forwards to lie immediately behind the optic chiasma. Rostrally the tumour had a fairly firm attachment to the tuber cinereum, a feature in which it differed from that in case 1 . It was estimated to be about $2 \mathrm{~cm}$. in diameter. Removal was piecemeal and complete, except perhaps for a few tags at its point of attachment to the brain. Eventually the rostral end of the basilar artery was seen across the resulting cavity. In appearance and texture the tumour was similar to that encountered in case 1 .

Closure of the wound and the post-operative course were uneventful. The child made an excellent recovery and was returned to his home on 27 August 1962.

Macroscopic pathology (S.D. 4833/62) About 12 fragments of white tissue, each measuring up to 0.4 by $0.2 \mathrm{~cm}$., mixed with some blood clot were received.

Microscopic pathology The appearances so closely resemble those described in case 1 that they need no repetition except for three points. First, the fragmentary nature of the tissue precludes the tracing of any relationship of the bundles of myelinated nerve fibres to the surface of the hamartoma. Secondly, there are no foci of small, undifferentiated cells such as were noted in case 1 . Thirdly, no neurosecretory substance was detected, by special staining, in any part of the tissue examined.

Subsequent course The patient returned to Malaya with his parents in October 1962. His doctor there wrote

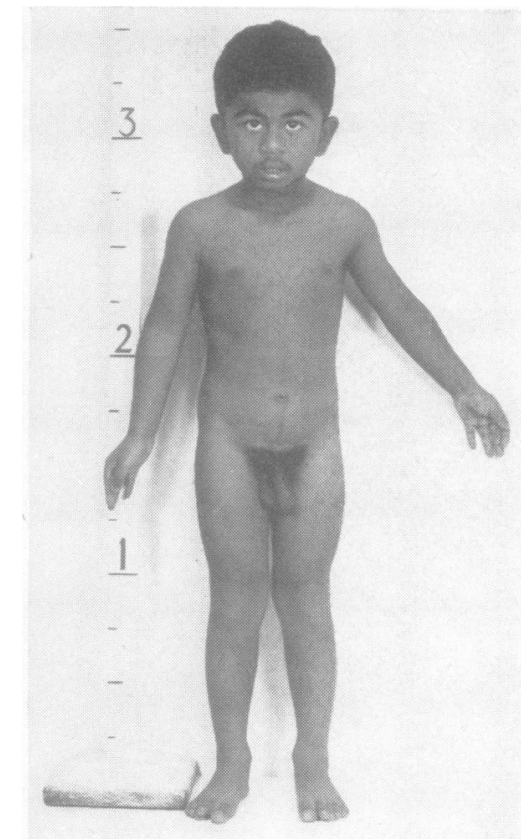

FIG. 7. S.D. (case 2) aged 3 years 9 months.
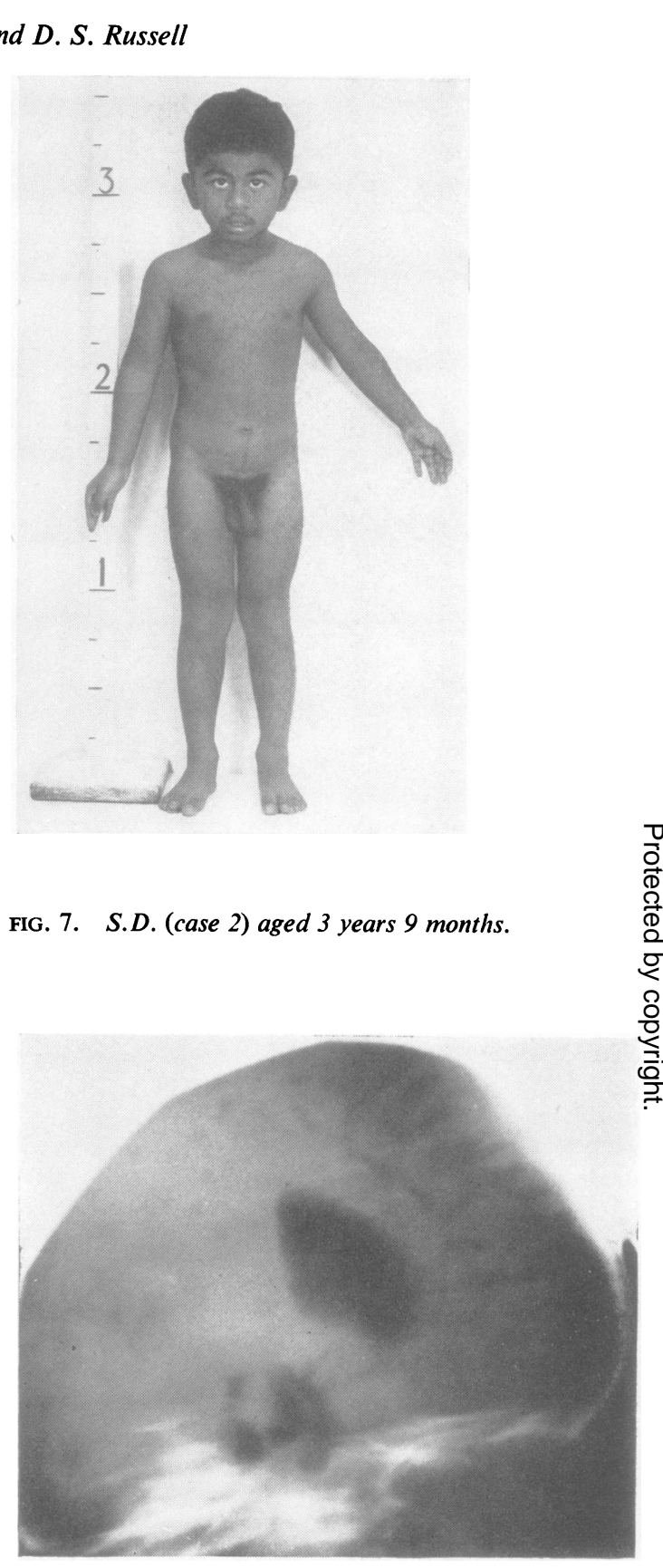

FIG. 8. A.E.G. in case 2 (see text).

on 24 March 1966, that, in 1963, the child had some headaches which passed off. In January 1966, he had some attacks of what appeared to be paroxysmal tachycardia. Otherwise his health has been good. He is reported as emotionally normal for his age, is intelligent and attending school. The genitalia are still of adult type but, 
according to the mother, he has no abnormal sexual interests. The head is $54 \mathrm{~cm}$. in circumference, and height $4 \mathrm{ft} .3 \frac{1}{2}$ in. $(1 \cdot 3 \mathrm{~cm}$.).

\section{NOTE ON RADIOLOGICAL APPEARANCES AND OPERATIVE PROCEDURE}

Air encephalography is essential to the diagnosis of these lesions. The tumour lies below the floor of the third ventricle in the basal cisterns, which must be filled with air in order to outline the mass. Ventriculography rarely fills the cisterns, and without their demonstration a filling defect in the floor of the third ventricle (due to its indentation by the tumour) may be erroneously ascribed to an intrinsic tumour of the floor. The radiological appearances of both these cases are remarkably similar, and quite unlike those of other tumours in this region, such as craniopharyngioma, pituitary adenoma, and glioma of the optic chiasma and of the hypothalamus. In the first case, the appearance was quite unfamiliar to one of us (D.W.C.N.) but was immediately recognized by the other (D.S.R.) by reason of her previous experience of the morbid anatomy of these rare lesions (Le Marquand and Russell, 1934-35).

The situation of the tumour appeared to be surgically inaccessible, and in the first case the mother gave her permission for the right optic nerve to be divided, if this proved necessary in order to remove the tumour. In the event this was not necessary. After the right optic nerve had been cleared of arachnoid the tumour was immediately perceived, in the interval between the lateral border of the nerve and the internal carotid artery (Fig. 9). The tumour had displaced the nerve in a rostral and medial direction, and the artery in a ventral and lateral direction, thereby enlarging the interval between these structures. After removing a small portion of the anterior frontal operculum, to gain room for manoeuvre, it was possible to remove the tumour through the space between the optic nerve and the carotid artery.

In the second case, the tumour was not immediately visible, and the only apparent abnormality was a rather long right optic nerve, separated from the internal carotid artery by a wide interval. Inspection medial to the optic nerve revealed the pituitary stalk lying in a more anterior plane than is usual, as though it were pressed forwards against the chiasma; further dissection and more careful scrutiny between the optic nerve and the carotid artery brought to light the mass, which was removed piecemeal through this interval. It was not necessary to remove any frontal lobe in this case.

Details of the operative procedure have been described because it is commonly held that retro-

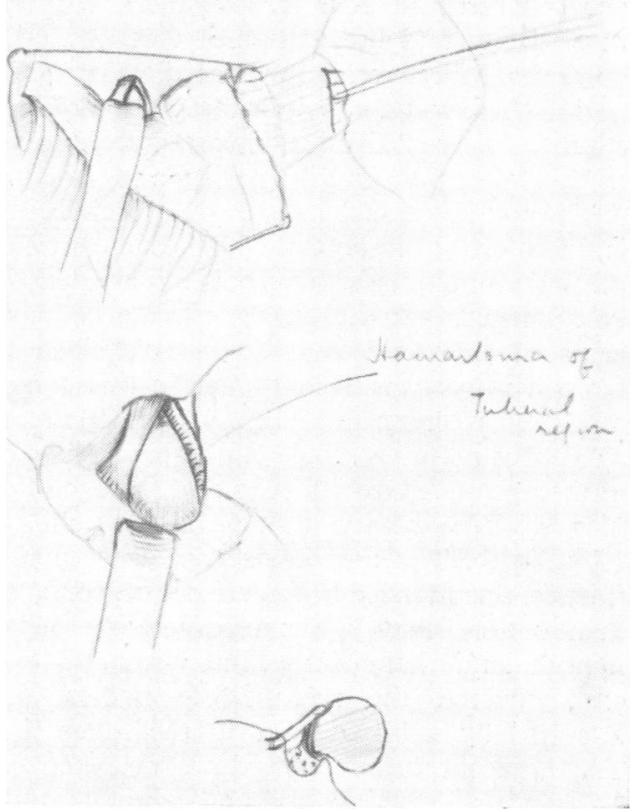

FIG. 9. Operation sketch in case 1 .

chiasmal tumours cannot be approached between the optic nerve and carotid artery. This is not the case. The interval is usually widened by the tumour, and provided meticulous care is taken to avoid any trauma to the optic nerve, this route provides a further means of reaching other posteriorly placed tumours or their extensions, such as pituitary adenoma and craniopharyngioma.

\section{DISCUSSION}

In pubertas praecox a well-defined group of cases is of the kind described in this paper. Therapeutically it is of importance to assess the benefits that may accrue from operative removal of the offending hamartoma. In case 1 the patient has survived operation for eight years, in case 2 for nearly four years.

In neither case has the excessive development of the external genitalia undergone regression. Possibly it would be over-optimistic to expect this, and testicular biopsy would be necessary to determine whether cellular activity in the seminiferous tubules had subsided. Neither patient displayed undue interest in the opposite sex at any time, so this criterion also is lacking.

The repercussions of operation upon bodily growth, however, have been more obvious. In both 
cases there has been a gradual increase in stature accompanied, in case 1 , by a loss of excessive muscularity and the assumption of normal bodily contours. Moreover, in the immediate post-operative period there was an obvious retardation of growth in stature. In case 2 there is, unfortunately, no mention of this latter point by the patient's Malayan doctor.

The continued skeletal growth, especially in case 1 , is manifestly important. Whilst continuity of pituitary function is thereby demonstrated, it must be admitted that the progress to be anticipated in cases of this kind is unpredictable since survival beyond puberty is exceptional. In this context the report by Wolman and Balmforth (1963) of a woman aged 62 is pertinent. She evinced precocious puberty at the age of 7 . Growth ceased at the age of 9 years. Her height was then $4 \mathrm{ft}$. $6 \frac{1}{2}$ in. and she weighed $15 \mathrm{st} .6 \mathrm{lb}$. The menopause occurred in the early thirties. She married but never became pregnant. No mental abnormality was recorded. At necropsy a hypothalamic hamartoma, measuring $1.5 \times 1 \times 1$ $\mathrm{cm}$., covered the mammillary bodies and was attached by a broad base to the tuber cinereum. The adjacent brain showed no evidence of compression or distortion, and both pituitary and pineal glands appeared normal.

The significance of mental retardation in case 1 is difficult to assess. It is an inconstant feature in these patients and its pathological background has not been established. The boy in case 1 has improved in this respect, but he is still subnormal for his age.

Finally attention is called to the difficult problem of the means whereby pubertas praecox is evoked by this type of lesion. Mounting evidence of the importance of hypothalamic mechanisms in the control and regulation of the production of pituitary hormones (see review by Reichlin, 1963) suggests that excitation of gonadotrophic secretion is caused by the presence of the hamartoma. Its anatomical relationship to the posterior part of the tuber cinereum and mammillary bodies is sufficiently constant to suggest that this site is of crucial importance in provoking the syndrome of pubertas praecox. Wolman and Balmforth have studied the nature of the neural connexions bridging the hamartoma and hypothalamus and found, in their case, that bands of nerve fibres blended with the capsule of the adjacent mammillary body. Furthermore, they demonstrated neurosecretory material in some of the nerve cells in the hamartoma. From this they concluded 'that the hamartoma acts as an overdrive to the posterior hypothalamic area, using a neurosecretory mechanism'.

This argument holds only if there is a union of this kind between the hamartoma and the hypothalamus. It is apparently supported by the case described by Bedwell and Lindenberg (1961) in a 19-year-old negro male, without any history of pubertas praecox, who died as a result of a motor accident. A spherical hamartoma, approximately $1 \mathrm{~cm}$. in diameter, was found adjacent to the tuber cinereum. It was devoid of any neural connexions and 'caused only a mild depression of the right half of the tuber cinereum'. On the other hand, in our case 1 there was seemingly no attachment of the hamartoma to the brain. This was, at operation, in sharp distinction to the findings in case 2 and it seems unlikely that any firm union could have been overlooked. If this is acceptable, then it must be conceded that a peduncular attachment to the brain is not essential for the development of pubertas. praecox.

Excitation of the hypothalamic centres by pressure alone might be more in accordance with the available data. Thus we have on record the case of a woman aged 34 (P.M. 277.1955) who had no history of pubertas praecox. She died from cerebral sarcoidosis. A pale grey nodule, measuring $0.9 \mathrm{~cm}$. from side to side by $0.85 \mathrm{~cm}$. from above down by $0.5 \mathrm{~cm}$. anteroposteriorly, was attached to the tuber cinereum just in front of the right mammillary body. Micro scopically the cellular features were more suggestive of a ganglioneuroma than the classical type of o hamartoma. However, Horrax, and Bailey (1928, 응 case 3) recorded pubertas praecox in association witk $\rightarrow$ a ganglioneuroma of the hypothalamus, and it must be insisted that the cytological character of the hypothalamic mass has apparently no bearing off $\vec{\bullet}$ the clinical picture of pubertas praecox. Thus, in addition to ganglioneuroma, there are records of a similar disturbance in association with hypothalamic astrocytomas, ependymal glioma, craniopharyngioma and, notably, pineal tumours (see Russell and Rubinstein, 1963), the majority of which are teratomas.

Taking all these points into consideration, there are formidable objections to the theory advanced by Wolman and Balmforth. It would seem far more likely that the excitatory factor is purely mechanical in its action. If so, it would seem necessary that the hamartoma, or tumour, should attain a critical volume before its endocrine effects became manifest, and we would argue that this may explain the observations (noted above) in which a hypothalamic hamartoma is dissociated from the condition of pubertas praecox.

\section{SUMMARY}

Two cases of pubertas praecox are described in each of which a hypothalamic hamartoma was removed. Both patients are alive eight and four years respectively after the operation. 
The appearance at air encephalography and the operative approach are described.

The mechanisms which may excite pubertas praecox in these and similar cases are discussed.

\section{REFERENCES}

Bedwell, S. F., and Lindenberg, R. (1961). Hypothalamic hamartoma with dendritic proliferation and other neuronal changes associated with 'blastomatoid' reaction of astrocytes. $J$. Neuropath. exp. Neurol., 20, 219-236.

Horrax, G., and Bailey, P. (1928). Pineal pathology-further studies. Arch. Neurol. Psychiat. (Chic.), 19, 394-414.
Le Marquand, H. S., and Russell, D. S. (1934-35). A case of pubertas praecox (macrogenitosomia praecox) in a boy associated with a tumour in the floor of the third ventricle. Roy. Berks. Hosp. Rep., 3, 31-61.

List, C. F., Dorman, C. E., Bagchi, B. K., and Bebin, J. (1958). Posterior hypothalamic hamartomas and gangliogliomas causing precocious puberty. Neurology (Minneap.), 8, 164-175.

Reichlin, S. (1963). Neuroendocrinology. New Engl. J. Med., 269, $1182-1189$; 1246-1250; 1296-1303.

Russell, D. S., and Rubinstein, L. J. (1963). Pathology of Tumours of the Nervous System, 2nd ed. Arnold, London.

Schmidt, E., Hallervorden, J., and Spatz, H. (1958). Die Entstehung der Hamartome am Hypothalamus, mit und ohne Pubertas Praecox. Disch. $Z$. Nervenheilk., 177, 235-262.

Wolman, L., and Balmforth, G. V. (1963). Precocious puberty due to a hypothalamic hamartoma in a patient surviving to late middle age. J. Neurol. Neurosurg. Psychiat., 26, 275-280. 